face. The accompanying tracings from Catherwood's work will sufficiently explain my meaning.

Fig. I, from the gateway at Labnah, pl. xix. ; Fig. 2, from the gateway of the great Teocallis Uxmal, pl. xii.; Fig. 3 , from

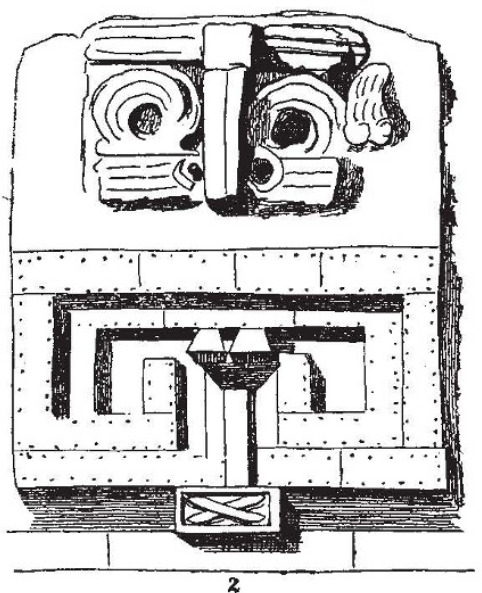

FIG. 2.-Gateway of the Great Teocallis Uxmal (Plate r2).

Las Monjas Chichen Itza, pl. xxi., illustrate the development of the fret. Fig. 4, from Las Monjas Chichen Itza, pl, xxi., shows another modification of the human face.

In his "Grammar of Ornament" Owen Jones says (p. 35) :

"In Mr. Catherwood's illustrations of the architecture of Yucatan

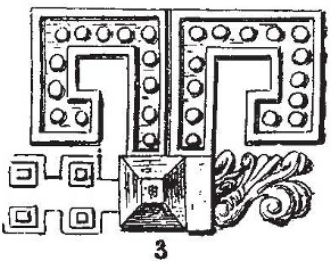

Fig. 3.-Las Monjas Chichen Itza (Plate zr).

we have several varieties of the Greek fret: one especially is thoroughly Greek. But they are, in general, fragmentary like the Chinese." The reason I would assign for this "fragmentary" nature of the design is that it was just passing from the disjointed ornament to the pattern stage. An examination of the plates
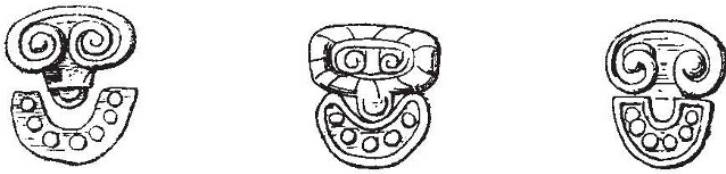

Fig. 4.-Las Monjas Chichen Itza (Plate 21).

will prove the profuse employment of the more or less grotesquely modified human face in mural decoration.

The hypertrophy of one set of organs, with the atrophy of another, and modification of a third, are paralleled in the specialisations of all degraded forms. ALFRED C. HADDON

Zoological Museum, Cambridge

\section{Temperature of the Breath}

I AM unable to see what bearing "I. J. M. P.'s" suggestion that I should try the effect of dipping my thermometer, enveloped in a tightly-rolled handkerchief, in water at $108^{\circ}$ has on this subject. Every one of course knows that a thermometer in such circumstances would eventually acquire the temperature of the water in which it is immersed.

The state of the matter is simply this: On the one hand works on physiology agree in stating that the normal temperature of the breath is from $95^{\circ}$ to $97^{\circ}$, and that of the interior of the body from $98^{\circ} .5$ to $99^{\circ} .5$. These are what Mr. McNally would call "ascertained physiological truths." On the other hand I find that by breathing on the bulb of a thermometer enveloped in about twenty folds-more or less-of a silk, cotton, or woollen cloth for five minutes, the thermometer indicates temperatures varying-owing to conditions not yet precisely ascertainedfrom $102^{\circ}$ to $108^{\circ}$, which, as every one knows, are temperatures vastly greater than the accepted temperature of the breath or interior of the body.

There is no question of squeezing up the reading of a delicate thermometer by the tightness of the enveloping material, for the thermometer used in these experiments is an ordinary clinical thermometer, such as I use daily in practice, the bulb of which is made of such stout glass that no amount of pressure short of breaking the bulb will move the mercury in the slightest degree.

The following variation in the mode of experimenting precludes the passibility of any pressure on the thermometer. I put the thermometer in a glass tube about three-fourths of an inch bore, open at both ends, packed the stem loosely with cotton wool but left the bulb free at one end of the tube. I then enveloped the whole in a silk handkerchief and breathed through twelve folds of the material into the end of the tube where the bulb of the thermometer was, untouched by cotton wool, glass tube, or silk handkerchief. After five minutes the thermometer showed a temperature of $102^{\circ}$. In this case, and I believe also in $\mathrm{my}$ former experiments, the enveloping material merely acted as a bad conductor, retaining the heat produced by the breath.

As any one can easily repeat these experiments for himself, $I$ would suggest to your correspondents that they should do so When the facts have been established by reiterated experiments -my own observations have been corroborated by several of my friends - the explanation or significance of them will ino doubt be speedily arrived at. Provisionally I suggest that these observations show respiration to be a powerful agent for getting rid of the superfluous caloric of the body.

How is this heat communicated to the breath? If it had anything to do with the conversion of the carbon of the blood into carbonic acid, the quantity of carbonic acid passed off by the breath would be greater when the temperature of the latter is higher, less when it is lower. But Letellier's experiments show that the amount of carbonic acid exhaled is greatly increased by external cold, and diminished by heat; whereas my experiments apparently show that the temperature of the breath is lower in external cold, higher in heat.

To solve the questions suggested by these experiments one would require the aid of a physiological laboratory, but as that is not at my command, and, moreover, as I could not devote the necessary time to them, I must leave their solution to others.

October 20

R. E. DUDGEON

\section{Soaring of Birds}

I BEG to send you some data on the above subject, as I live where the phenomenon is of daily occurrence. Most of the large birds out here soar, i.e. can circle round and round without flapping the wings, and also can rise thus from 100 or 200 feet to some 8,000 by same means. The pelican, the adjutant, and several large birds allied to it, the vulture and the cyrus, rise thus.

Firstly they rise by flapping the wings vigorously, and when up some 100 or 200 feet, if there is a breeze, begin to soar in large circular sweeps, rising to to 20 feet at each lap, the whole bird being otherwise quite motionless, and the wings extended rigidly.

We have two steady winds here, from north east and west south-west, and in one of these the birds rise to great heights, and can be seen as small specks up in the blue, and watched with telescope, going round and round, motionless otherwise. The following data are trustworthy:- The birds weigh from 20 to 40 lbs.; spread of wings, 10 to 12 feet ; stand 3 to 5 feet high; speed flying or soaring, about 15 to 35 miles per hour (estimated).

They rise by flapping the wings. If there is no wind they $\left\{\begin{array}{l}\text { do not } \\ \text { cannot }\end{array}\right.$ soar; they generally begin to soar at 100 to 200 feet elevation when above the level of the forest. In soaring they $\left\{\begin{array}{l}\text { do not } \\ \text { cannot }\end{array}\right\}$ go in a right line, but in large curves of a spiral that leans to leeward.

At each lap they can rise 10 to 20 feet, but lose position laterally of 20 to 50 feet to leeward. The soaring can go on without once flapping the wings, till the bird is almost out of sight.

If near, the feather-tips make a loud musical "sing," and the precence often first known by it. If watched, they come 